\title{
Species-Specific Identification of Human Adenoviruses in Sewage
}

\author{
MAGDALENA WIECZOREK*, ARLETA KRZYSZTOSZEK and AGNIESZKA WITEK \\ National Institute of Public Health, National Institute of Hygiene \\ Department of Virology, Warsaw, Poland
}

Submitted 21 August 2014, revised 10 December 2014, accepted 23 December 2014

\begin{abstract}
Human adenovirus (HAdV) diversity in sewage was assessed by species-specific molecular methods. Samples of raw sewage were collected in 14 sewage disposal systems from January to December 2011, in Poland. HAdVs were detected in $92.1 \%$ of the analysed sewage samples and was significantly higher at cities of over 100000 inhabitants. HAdV DNA was detected in sewage during all seasons. The most abundant species identified were HAdV-F (average 89.6\%) and -A (average 19.6\%), which are associated with intestine infections. Adenoviruses from $\mathrm{B}$ species were not detected. The result of the present study demonstrate that human adenoviruses are consistently present in sewage in Poland, demonstrating the importance of an adequate treatment before the disposal in the environment. Multiple HAdV species identified in raw sewage provide new information about HAdV circulation in the Polish population.
\end{abstract}

Ke y words: adenoviruses' detection, sewage, species-specific identification

\section{Introduction}

Human adenoviruses (HAdVs) are members of the Adenoviridae family, group of medium-sized viruses characterized by a nonenveloped icosahedral nucleocapsid and a double stranded DNA genome. The Adenoviridae family consists of five genera, of which the genus Mastadenovirus includes human viruses classified into 57 serotypes clustered into 7 subgroups (A-G). Human adenoviruses have different organ tropisms, causing a wide variety of clinical manifestations including respiratory tract infections, acute conjunctivitis, cystitis, gastroenteritis and systemic infections in immunocompromised patients. Subgroup A, F and $\mathrm{G}$ species primarily infect the gastroenteric tract, but only types 40 and 41 (subgroup F) have been strongly associated with gastroenteritis. Enteric adenoviruses multiply in the gastrointestinal tract, and are excreted in large numbers in the faeces of infected persons (even more than $10^{8}$ copies/g of stool). The main source of adenoviruses in the environment is human faecal matter. Viruses cannot replicate outside their host's tissues and therefore cannot multiply in the environment; however, they can survive in the environment for extended periods of time and have good tolerance for changing environmental conditions. HAdVs are extremely common in wastewater throughout the year, with concentrations between $10^{3}$ and $10^{7}$ genome copies/L reported in municipal wastewater from different geographical areas (Katayama et al., 2008; Fong et al., 2010; Kishida et al., 2012; Rodriguez et al., 2013;). In seawater, the enteric adenoviruses have been shown to be substantially more stable than either polio 1 or hepatitis A virus (Enriquez and Gerba, 1995). Many studies have suggested that HAdV is a good candidate as a fecal pollution indicator because of its known stability and persistence in aquatic environments compared to other enteric viruses (Pina et al., 1998; Hundesa et al., 2006; Albinana-Gimenez et al., 2009; Fong et al., 2010; Hewitt et al., 2013).

During the last years, more attention has been focused on the sewage virological quality, the risk of virus-associated waterborne illness, the need for routine monitoring viral contamination and the environmental surveillance through the analysis of sewage. The presence of enteric viruses in sewage and hence in environmental surface waters reflects the infectious status of the population and constitutes a public health risk. The aim of this study was species-specific identification of human adenoviruses in sewage from Poland. Sewage samples from 14 sewage disposal systems in Poland (located in 13 towns) were examined for the presence of adenoviruses by molecular methods. Predominant adenovirus species in sewage were determined.

\footnotetext{
* Corresponding author: M. Wieczorek, National Institute of Public Health, National Institute of Hygiene, Department of Virology, Warsaw, Poland; e-mail: mrechnio@pzh.gov.pl
} 


\section{Experimental}

\section{Materials and Methods}

Sewage samples. Samples of raw sewage were collected in 14 sewage disposal systems from January to December 2011, one sample a month. A total of 163 sewage samples were processed according to the protocol described earlier (Zurbriggen et al., 2008). To describe the process briefly, $\mathrm{AlCl}_{3}$ (final concentration, $0.5 \mathrm{mM}$ ) was added to $500 \mathrm{ml}$ of sewage sample, and the $\mathrm{pH}$ was adjusted to 3.5. Following the addition of $250 \mu \mathrm{l}$ of a $\mathrm{SiO}_{2}$ slurry, the samples were stirred for $30 \mathrm{~min}$., followed by centrifugation at room temperature and $1500 \times \mathrm{g}$ for $5 \mathrm{~min}$. to pellet the $\mathrm{SiO}_{2}$. The virus was recovered by rocking the pellet for $20 \mathrm{~min}$. with $3 \mathrm{ml}$ of $50 \mathrm{mM}$ glycine (pH 9.5) containing $3 \%$ (wt/vol) beef extract. After centrifugation for $5 \mathrm{~min}$. at $4^{\circ} \mathrm{C}$ and $1500 \times \mathrm{g}$, the concentrates were used to DNA extraction.

DNA extraction and PCR. Viral DNA was extracted from $100 \mu \mathrm{l}$ of concentrated sewage using spin columns (QIAamp DNA stool kit - Qiagen) following the manufacturer's instructions. PCR was carried out using human adenovirus group-specific primers complementary to regions of the hexon gene (ADV-F, ADV-R) and HAdV species-specific primers (Table I). PCR amplification was performed in $25 \mu \mathrm{l}$ volumes containing $23 \mu \mathrm{l}$ of reaction mixture (Platinum PCR SuperMix with additions of $200 \mathrm{nM}$ of each primer) and $2 \mu \mathrm{l}$ of DNA extract. Amplification with groupspecific starters started with an initial denaturation at $94^{\circ} \mathrm{C}$ for $5 \mathrm{~min}$., followed by 30 cycles of denaturation at $94^{\circ} \mathrm{C}$ for $30 \mathrm{~s}$, annealing at $60^{\circ} \mathrm{C}$ for $30 \mathrm{~s}$, extension at $72^{\circ} \mathrm{C}$ for $30 \mathrm{~s}$, and final extension at $72^{\circ} \mathrm{C}$ for $5 \mathrm{~min}$. Reaction mixtures were then held at $4^{\circ} \mathrm{C}$. Amplifica- tion with species-specific starters started with an initial denaturation at $94^{\circ} \mathrm{C}$ for $5 \mathrm{~min}$., followed by 30 cycles of denaturation at $94^{\circ} \mathrm{C}$ for $60 \mathrm{~s}$, annealing at $56^{\circ} \mathrm{C}$ for $60 \mathrm{~s}$, extension at $72^{\circ} \mathrm{C}$ for 120 s., and final extension at $72^{\circ} \mathrm{C}$ for $5 \mathrm{~min}$. Reaction mixtures were then held at $4^{\circ} \mathrm{C}$. Amplification products were analysed in $1 \%$ agarose gels, GelRed-stained and viewed with the Molecular Imager Gel Doc system (BioRad Laboratories Inc.).

Statistical analysis. To identify statistical significance, a Student's $t$ test analysis was performed online (http://www.physics.csbsju.edu/stats/). Results with $p$ values of less than 0.05 were considered significant.

\section{Results}

Sewage samples were collected each month from each sampling site. In total, 163 samples of raw sewage were investigated by molecular methods. Out of the 163 samples analysed, 150 were positive for human adenoviruses using HAdV group-specific primers (92.1\%). The percentage of PCR-positive samples in different sampling months was $76.9 \%$ (October) to $100 \%$ (February, March, June, July, August, November) (Fig. 1). The percentage of PCR-positive samples at the different sampling sites range between $75 \%$ and $100 \%$ and was significantly higher at cities of over 100000 inhabitants ( $\mathrm{p}=0.027)$ (Fig. 2).

A total of 163 sewage samples were examined for the presence of A, B, C, D, E and F species of human adenoviruses by molecular methods using species-specific primers. Adenoviruses from species A were found in 32 specimens (19.6\%). The percentage of positive samples in different sampling months was 7.1\% (June, July, September) to $57.1 \%$ (March) (Fig. 1), with the highest

Table I

Oligonucleotide primers used in this study.

\begin{tabular}{|c|c|c|c|c|}
\hline Target & Name & Sequence $\left(5^{\prime} \rightarrow 3^{\prime}\right)$ & Amplicon size (bp) & References \\
\hline \multirow[t]{2}{*}{ Human adenovirus } & ADV-F & GCCACGGTGGGGTTTCTAAACTT & \multirow[t]{2}{*}{131} & \multirow[t]{2}{*}{ Gunson et al., 2009} \\
\hline & ADV-R & GCCCCAGTGGTCTTACATGCACATC & & \\
\hline \multirow[t]{2}{*}{ HAdV species A } & AdA1 & GCTGAAGAAMCWGAAGAAAATGA & \multirow[t]{2}{*}{$1444-1537$} & \multirow[t]{2}{*}{ Xu et al., 2000} \\
\hline & AdA2 & CRTTTGGTCTAGGGTAAGCAC & & \\
\hline \multirow[t]{2}{*}{ HAdV species B } & AdB1 & TSTACCCYTATGAAGATGAAAGC & \multirow[t]{2}{*}{$670-772$} & \multirow[t]{2}{*}{ Xu et al., 2000} \\
\hline & AdB2 & GGATAAGCTGTAGTRCTKGGCAT & & \\
\hline \multirow[t]{2}{*}{ HAdV species $C$} & AdC1 & TATTCAGCATCACСТCСТTTCC & \multirow[t]{2}{*}{$1988-2000$} & \multirow[t]{2}{*}{ Xu et al., 2000} \\
\hline & AdC2 & AAGCTATGTGGTGGTGGGGC & & \\
\hline \multirow[t]{2}{*}{ HAdV species D } & AdD1 & GATGTCAAATTCCTGGTCCAC & \multirow[t]{2}{*}{$1205-1221$} & \multirow[t]{2}{*}{ Xu et al., 2000} \\
\hline & AdD2 & TACCCGTGCTGGTGTAAAAATC & & \\
\hline \multirow[t]{2}{*}{ HAdV species E } & AdE1 & TCCCTACGATGCAGACAACG & \multirow[t]{2}{*}{967} & \multirow[t]{2}{*}{ Xu et al., 2000} \\
\hline & AdE2 & AGTGCCATCTATGCTATCTCC & & \\
\hline \multirow[t]{2}{*}{ HAdV species F } & AdF1 & ACTTAATGCTGACACGGGCAC & \multirow[t]{2}{*}{$541-586$} & \multirow[t]{2}{*}{ Xu et al., 2000} \\
\hline & AdF2 & TAATGTTTGTGTTACTCCGCTC & & \\
\hline
\end{tabular}




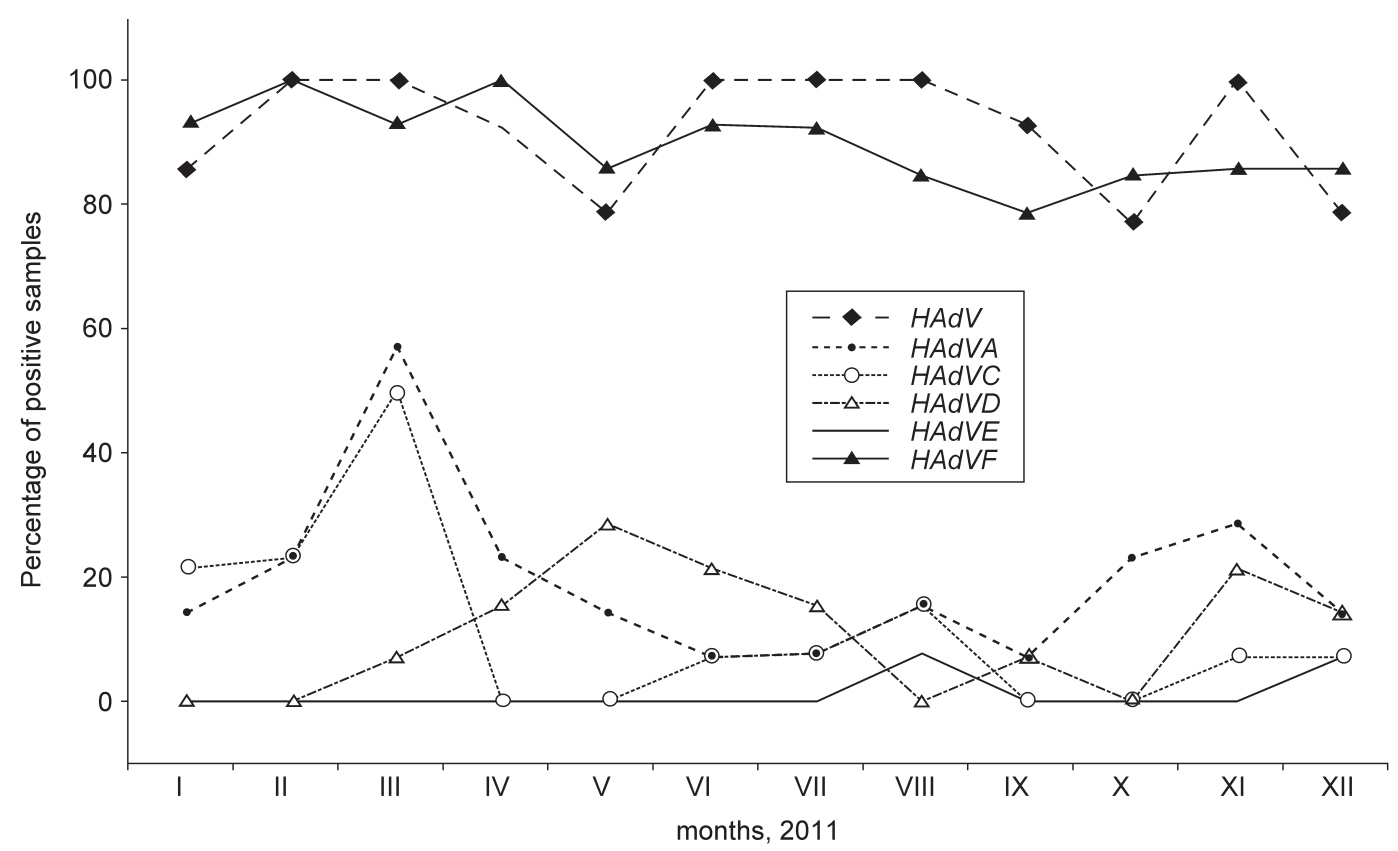

Fig. 1. Adenovirus positive sewage samples depending on season.

detection rate in the winter and early spring. The percentage of samples positive at the different sampling sites ranged between $0 \%$ and $58.3 \%$ and was higher at cities of over 100000 inhabitants (not significantly different). Adenoviruses from $B$ species were not detected in sewage. Adenoviruses from species $\mathrm{C}$ were found in 19 specimens (11.6\%). The percentage of positive samples in different sampling months was $0 \%$ (April, May, September, October) to $50.0 \%$ (March) (Fig. 1). The percentage of samples positive at the different sampling sites ranged between $0 \%$ and $33.3 \%$ and was higher at cities of over 100000 inhabitants, this difference is not significant. Adenoviruses from species D

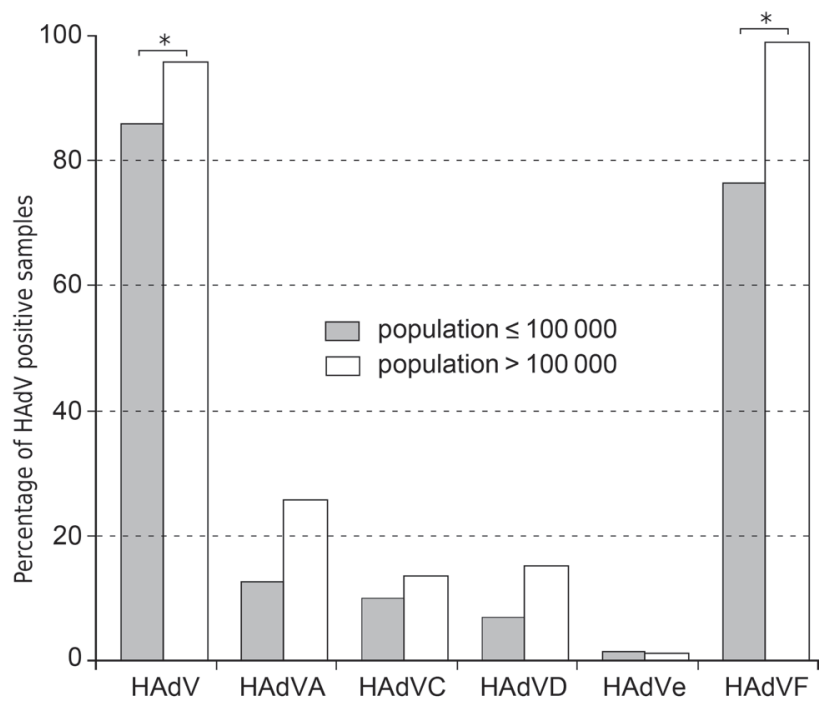

Fig. 2. Percentage of adenovirus positive sewage samples at cities with a population over and below 100000 inhabitants.

The asterisk indicates a statistically significant difference $(\mathrm{p}<0.05)$. were found in 18 specimens (11.0\%). The percentage of positive samples in different sampling months was $0 \%$ (January, February, August, October) to 28.6\% (May) (Fig. 1). The percentage of samples positive at the different sampling sites ranged between $0 \%$ and $37.5 \%$ and was higher at cities of over 100000 inhabitants (not significantly different). Adenoviruses from species $\mathrm{E}$ were found only in two specimens $(1.2 \%)$ collected in August and December from two different cities. Adenoviruses from species $\mathrm{F}$ were the most prominent species detected in sewage, they were found in 146 specimens $(89.6 \%)$. The percentage of positive samples in different sampling months was $78.6 \%$ (September) to $100 \%$ (February, April) (Fig. 1). The percentage of samples positive at the different sampling sites ranged between $50 \%$ and $100 \%$ and was significantly higher at cities of over 100000 inhabitants ( $\mathrm{p}=0.017)$ (Fig. 2).

\section{Discussion}

Adenoviruses have been detected in sewage worldwide. Recent metagenomic studies have shown that multiple types of viruses can be found in raw sewage (Cantalupo et al., 2011; Ng et al., 2012). In this study, sewage samples were used to detect of diversity of HAdVs in wastewater. Samples of sewage were collected from several locations around Poland. Samples were evaluated by PCR assay for the presence of human adenoviruses. Our investigation confirmed that sewage is a rich source of adenoviruses. HAdVs were detected in $92.1 \%$ of the analysed sewage samples and was significantly higher at cities of over 100000 inhabitants. 


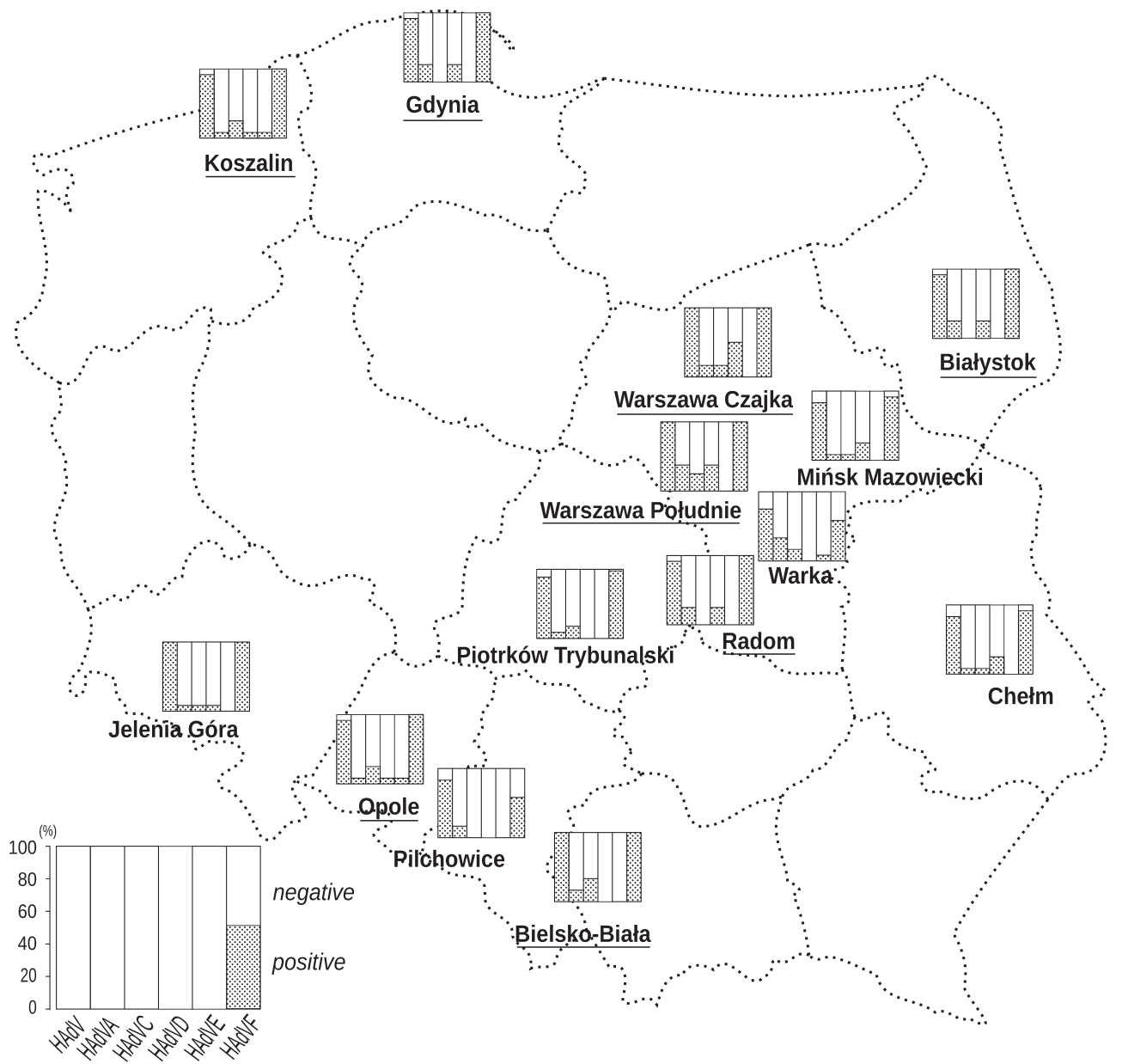

Fig. 3. Proportion of adenovirus positive and negative samples depending on sampling site (names of cities with population over 100000 are underlined).

Our results are in agreement with Puig et al. (1994), reporting detection of HAdVs in $100 \%$ of sewage. In other studies, HAdVs were detected in 56 and $20 \%$ of sewage and treated effluent samples, respectively (Pusch et al., 2005). Katayama etal. (2008) detected HAdVs in 100 and $99 \%$ sewage and treated effluent, respectively. Adenoviruses were detected in sewage during all seasons. Adenovirus infections have been observed to occur throughout the year with little or no seasonal variation in shedding. After infection, HAdV excretion by the host can last from months to years (Jiang, 2006) and the consequent lack of a seasonal pattern for this viruses in sewage has been confirmed by several studies (Jiang, 2006; Katayama et al., 2008).

All samples were subjected to species-specific PCR for detection human adenovirus species A, B, C, D, E, and F. Species F adenoviruses mainly, but also A, C, D, $G$ cause diseases of intestine. HAdV-A was identified as the etiologic agent of a diarrhea outbreak in a hematology hospital ward in London (Jalal et al., 2005). Recently, HAdV-D and -C were detected in faeces of children with diarrhea in Bangladesh, Kenya and Brazil (Jarecki-Khan et al., 1993; Filho et al., 2007; Magwalivha et al., 2010). In this study, species $F$ was identified as the predominant in sewage (89.6\%), followed by species A, $\mathrm{C}, \mathrm{D}$ and $\mathrm{E}$. We detected all species of human adenoviruses associated with intestine infections. Seasonal differences in detection were observed for species A, C (peak in March) and D (peak in May). Probability of detection of species $\mathrm{F}$ in sewage was determined by population size. Adenoviruses from species $\mathrm{F}$ were detected in 99\% samples at cites over 100000 inhabitants. This trends agrees with results from other environmental studies. Barrella et al. (2009) detected the presence of human adenovirus from species $\mathrm{F}$ in $82 \%$ of sewage samples. Fong et al. (2010) isolated adenoviruses from species F (63\%), A (29\%), B (3\%) and C (3\%) from raw sewage and primary effluents. Santos et al. (2004) isolated adenoviruses 40 and 41 (species F) from 62 of 69 sewage and surface water samples collected in San Paulo, Brazil, over a 3-year period. In South Africa, species F, D and C (serotype 2) were isolated from treated drinking water and river water, human adenovirus species $\mathrm{D}$ isolates were predominant in treated drinking water (van Heerden et al., 2005). Adenovirus species $\mathrm{F}$ has been identified as one of the most prevalent 
viruses globally in the etiology of childhood gastroenteritis. The HAdV serotypes 40 and 41 (species F) have long been recognized as the main etiological agents of $1-20 \%$ of acute viral gastroenteritis in children (Cruz et al., 1990; Jothikumar et al., 2005; Shimizu et al., 2007). Shimizu et al. state that $50 \%$ of all adenoviruses found in stool specimens are types 40 and 41 (species F). HAdV-40 is known to be widespread in the European population, where it can cause outbreaks of gastroenteritis, mostly in children during winter. After infection, HAdV types 40 and 41 can cause mortalities as much as $50 \%$ in immunocompromised individuals (Echavarria, 2008). Considering that these viruses are shed for extended periods in faeces, urine, and respiratory secretions of infected persons (Jiang et al., 2006), their high prevalence in this study suggests a high incidence of species $\mathrm{F}$ infections in the host population. Several authors have suggested that the enteric serotypes 40 and 41 (genus F) dominate overall HAdV serotypes in sewage. Although some recent studies have demonstrated (Sinbanda and Okoh, 2012; Bibby and Peccia, 2013) that HAdV-C were more frequent detected in sewage and environmental samples than HAdV-F. In the present work HAdV-C were detected in $11.6 \%$ of the sewage samples, but study results differed depending on sampling site (from 0 to 33\%) and sampling month (from 0 to 50\%). Bibby and Peccia (2013) identified species $\mathrm{C}$ in $78 \%$ of sewage samples. These results do not seem to be divergent taking under consideration that Bibby and Peccia collected ten samples in winter months from five wastewater treatment plants, served population ranging from 100000 to 1000000 people.

In the present study, human adenoviruses in sewage were detected by direct nucleic acid amplification from sewage concentrates by PCR. A number of studies have demonstrated that PCR is more rapid and sensitive than cell culture for adenovirus detection and speciesspecific identification by PCR is a popular method used to conduct adenovirus characterization (Xu et al., 2000). Nevertheless serotyping of adenoviruses on the basis of sequencing of PCR products is potentially more informative. Methods used for the identification of human adenoviruses in raw sewage have many limitations, mainly due to the nature of the samples examined. Raw sewage usually contains organic compounds at high concentrations, which may inhibit PCR reaction.

In conclusion, this research demonstrates that human adenoviruses are consistently present in sewage in Poland. Human adenovirus species $\mathrm{F}$ was the most prominent adenovirus species detected in sewage, but molecular analyses indicated the presence of additional adenovirus species. HAdV species A, C, D and $\mathrm{E}$ were found in sewage samples, demonstrating the occurrence of multiple HAdV species in sewage. The presence of adenovirus species in sewage may repre- sent a public health risk particularly taking in account immunocompromised individuals. Raw wastewater represent a significant source of pathogens that has a potential to contaminate aquatic environments and very important is adequate treatment before the disposal in the environment.

\section{Acknowledgments}

This research was undertaken as part of 14/EM.1/2014. The authors thank Tobiasz Wieczorek for his help with the figures.

\section{Literature}

Albinana-Gimenez N., M.P. Miagostovich, B. Calgua, J.M. Huguet, L. Matia and R. Girones. 2009. Analysis of adenoviruses and polyomaviruses quantified by qPCR as indicators of water quality in source and drinking-water treatment plants. Water Res. 43: 2011-2019.

Barrella K.M., P. Garrafa, T.A. Monezi, C.M. Harsi, C. Salvi, P.A. Violante and D.U. Mehnert. 2009. Longitudinal study on occurrence of adenoviruses and hepatitis A virus in raw domestic sewage in the city of Limeira, Sao Paulo. Braz. J. Microbiol. 40: 102-107.

Bibby K. and J. Peccia. 2013. Prevalence of respiratory adenovirus species B and C in sewage sludge. Environ. Sci. Process Impacts. 15(2): 336-338

Cantalupo P.G, B. Calgua, G. Zhao, A. Hundesa, A.D. Wier, J.P. Katz, M. Grabe, R.W. Hendrix, R. Girones, D. Wang and others. 2011. Raw sewage harbors diverse viral populations. MBio. 2(5): e00180-11

Cruz J.R., P. Caceres, F. Cano, J. Flores, A. Bartlett and B. Torun. 1990. Adenovirus types 40 and 41 and rotaviruses associated with diarrhea in children from Guatemala. J. Clin. Microbiol. 28: 1780-1784.

Echavarria M. 2008. Adenoviruses in immunocompromised hosts. Clin. Microbiol. Rev. 21: 704-715.

Enriquez C.E. and C.P. Gerba. 1995. Concentration of enteric adenovirus 40 from tap, sea and waste water. Water Res. 29: 2554-2560. Filho E.P., N.R. da Costa Faria, A.M. Fialho, R.S. de Assis, M.M. Almeida, M. Rocha, M. Galvao, F.B. dos Santos, M.L. Barreto and J.P. Leite. 2007. Adenoviruses associated with acute gastroenteritis in hospitalized and community children up to 5 years old in Rio de Janeiro and Salvador, Brazil. J. Med. Microbiol. 56: 313-319. Fong T.T., M.S. Phanikumar, I. Xagoraraki and J.B. Rose. 2010. Quantitive detection of human adenoviruses in wastewater and combined sewer overflows influencing a Michigan river. Appl. Environ. Microbiol. 76: 715-723.

Gunson R.N., A.R. Maclean, S.J. Shepherd and W.F. Carman. 2009. Simultaneous detection and quantitation of cytomegalovirus, Epstein-Barr virus, and adenovirus by use of real-time PCR and pooled standards. J. Clin. Microbiol. 47: 765-770.

Hewitt J., G.E. Greening, M. Leonard and G.D. Lewis. 2013. Evaluation of human adenovirus and human polyomavirus as indicators of human sewage contamination in the aquatic environment. Water Res. 47: 6750-6761.

Hundesa A., C. Maluquer, S. Biofill Mas, N.A. Gimenez and R. Girones. 2006 Idendification of human and animal adenoviruses and polyomaviruses for determination of sources of fecal contamination in the environment. Appl. Environ. Microbiol. 72: 7886-7893. Jalal H., D.F. Bibby, J.W. Tang, J. Bennett, C. Kyriakou, K. Peggs, D. Cubitt, N.S. Brink, K.N. Ward and R.S. Tedder. 2005. First 
reported outbreak of diarrhea due to adenovirus infection in a hematology init for adults. J. Clin. Microbiol. 43: 2575-2580.

Jarecki-Khan K., S.R. Tzipori and L.E. Unicomb. 1993. Enteric adenovirus infection among infants with diarrhea in rural Bangladesh. J. Clin. Microbiol. 31: 484-489.

Jiang S.C. 2006 Human adenoviruses in water: occurrence and health implications, a critical review. Environmental Science and Technology 40: 7132-7140.

Jothikumar N, T.L. Cromeans, V.R. Hill, X. Lu, M.D. Sobsev and D.D. Erdman. 2005. Quantitative real-time PCR assays for detection of human adenoviruses and identification of serotypes 40 and 41 . Appl. Environ. Microbiol. 71: 3131-3136.

Katayama H., E. Haramoto, K. Oguma, H. Yamashita, A. Tajima, H. Nakajima and S. Ohgaki. 2008: One-year monthly quantitative survey of noroviruses, enteroviruses, and adenoviruses in wastewater collected from six plants in Japan. Water Res. 42: 1441-1448. Kishida N., H. Morita, E. Haramoto, M. Asami and M. Akiba 2012. One-year weekly survey of noroviruses and enteric adenoviruses in the Tone River water in Tokyo metropolitan area. Japan. Water Res. 46: 2905-2910.

Magwalivha M., M. Wolfaardt, N.M. Kiulia, W.B. van Zyl, J.M. Mwenda and M.B. Taylor. 2010. High prevalence of species D human adenoviruses in fecal specimens from Urban Kenyan children with diarrhea. J. Med. Virol. 82: 77-84.

Ng T.F., R. Marine, C. Wang, P. Simmonds, B. Kapusinszky, L. Bodhidatta, B.S. Oderinde, K.E. Wommack and E. Delwart. 2012. High variety of known and new RNA and DNA viruses of diverse origins in untreated sewage. J. Virol. 86: 12161-12175.

Pina S., M. Puig, F. Lucena, J. Jofre and R. Girones. 1998. Viral pollution in the envir onment and in shellfish: human adenovirus detection by PCR as an index of human viruses. Appl. Environ. Microbiol. 64: 3376-3382.

Puig M., J. Jofre, F. Lucena, A. Allard, G. Wadell and R. Girones. 1994. Detection of adenoviruses and enteroviruses in polluted waters by nested PCR amplification. Appl. Environ. Microbiol. 60: 2963-2970

Pusch D., D.Y. Oh, S. Wolf, R. Dumke, U. Schroter-Bobsin, M. Hohne, I. Roske and E. Schreier. 2005. Detection of enteric viruses and bacterial indicators in German environmemtal waters. Arch. Virol. 150: 929-947.

Rodríguez R.A., P.M. Polston, M.J. Wu, J. Wu and M.D. Sobsey. 2013. An improved infectivity assay combining cell culture with real-time PCR for rapid quantification of human adenoviruses 41 and semi-quantification of human adenovirus in sewage. Water Res. 47: 3183-3191.

Santos F.M., M.J. Vieira, P. Garrafa, T.A. Monezi, V.H. Pellizari, C.M. Harsi and D.U. Mehnert. 2004. Discrimination of adenovirus types circulating in urban sewage and surface polluted waters in Sao Paulo city, Brazil. Water Sci. Technol. 4: 79-85.

Sibanda T. and A.I. Okoh. 2012. Assessment of the incidence of enteric adenovirus species and serotypes in surface waters in the eastern cape province of South Africa: Tyume River as a case study. The Scientific World Journal Article ID 949216

Shimizu H., T.G. Phan, S. Nishimura, S. Okitsu, N. Maneekarn and H. Ushijima. 2007. An outbreak of adenovirus serotype 41 infection in infants and children with acute gastroenteritis in Maizuru City, Japan. Infect. Genet. Evol. 7: 279-284.

Van Heerden J., M.M. Ehlers, A. Heim and W.O. Grabow. 2005. Prevalence, quantification and typing of adenoviruses detected in river and treated drinking water in South Africa. J. Appl. Microbiol. 99: 234-242.

Xu W., M.C. McDonough and D.D. Erdman. 2000. Species-specific identification of human adenoviruses by a multiplex PCR assay. J. Clin. Microbiol. 38: 4114-4120

Zurbriggen S., K. Tobler, C. Abril, S. Diedrich, M. Ackermann, M.A. Pallansch and A. Metzler. 2008. Isolation of sabin-like polioviruses from wastewater in a country using inactivated polio vaccine. Appl. Environ. Microbiol. 74: 5608-5614. 